Camille Cornand, Frank Heinemann

\title{
Monetary policy obeying the Taylor principle turns prices into strategic substitutes
}

Journal article | Accepted manuscript (Postprint)

This version is available at https://doi.org/10.14279/depositonce-9207

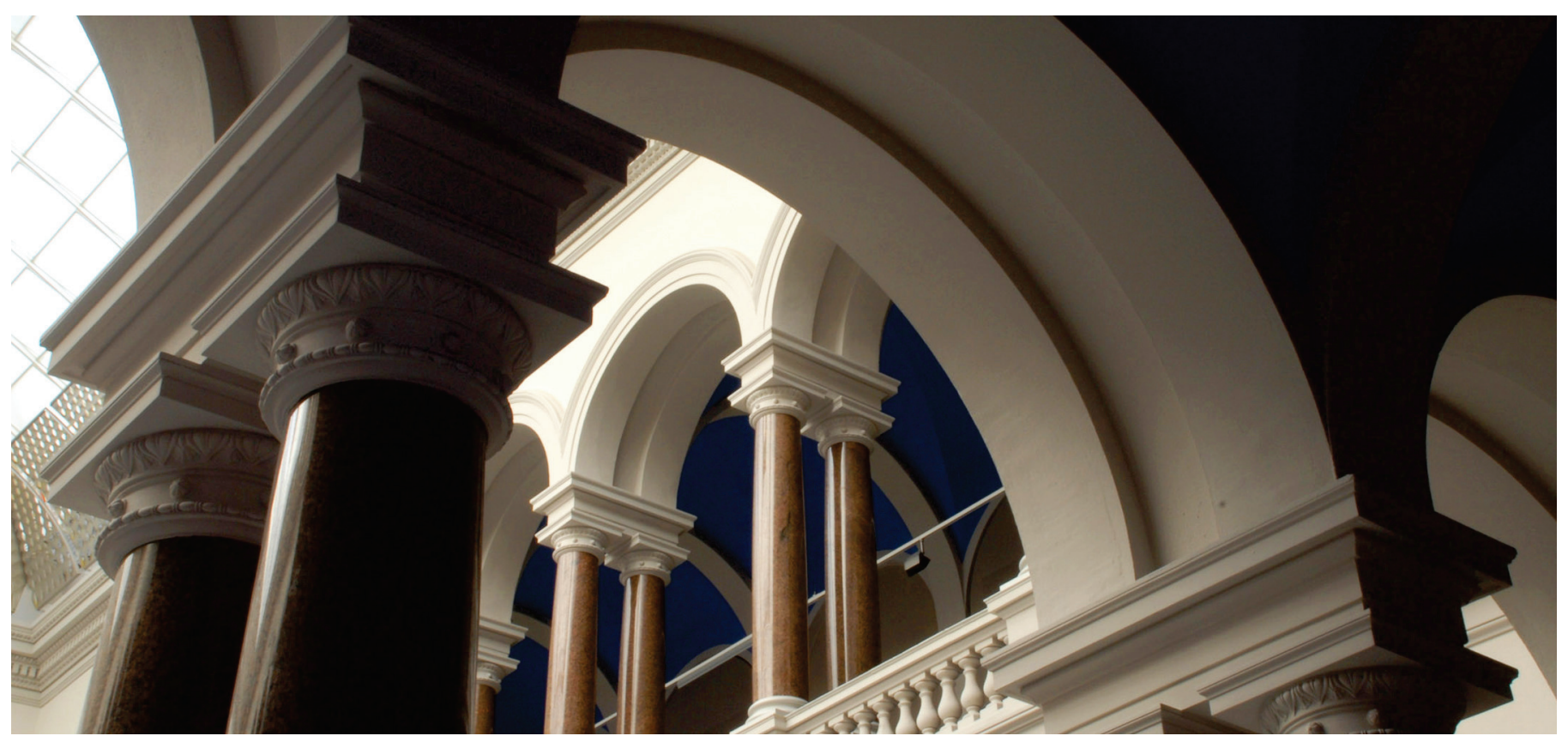

Cornand, C., \& Heinemann, F. (2019). Monetary policy obeying the Taylor principle turns prices into strategic substitutes. Journal of Economic Behavior \& Organization. https://doi.org/10.1016/j.jebo.2019.10.022 
This is the Accepted Manuscript of: Cornand, C., \& Heinemann, F. (2019). Monetary policy obeying the Taylor principle turns prices into strategic substitutes. Journal of Economic Behavior \& Organization. https://doi.org/10.1016/i.jebo.2019.10.022

This work is licensed under a Creative Commons Attribution-NonCommercial-NoDerivatives 4.0 International License, http://creativecommons.org/licenses/by-nc-nd/4.0/.

\title{
Monetary Policy obeying the Taylor Principle Turns Prices into Strategic Substitutes*
}

Camille Cornand and Frank Heinemann

October 11, 2019

\begin{abstract}
Monetary policy affects the degree of strategic complementarity in firms' pricing decisions if it responds to the aggregate price level. In normal times, when monopolistic competitive firms increase their prices, the central bank raises interest rates, which lowers demand and creates an incentive for firms to reduce their prices. Thereby, monetary policy reduces the degree of strategic complementarities among firms' pricing decisions and even turns prices into strategic substitutes if the effect of interest rates on demand is sufficiently strong. We show that this condition holds when monetary policy follows the Taylor principle. By contrast, if the equilibrium is indeterminate, because monetary policy violates the Taylor principle, or in a liquidity trap where monetary policy is restricted by the zero lower bound, pricing decisions are strategic complements. We discuss the consequences for dynamic adjustment processes after shocks and some policy implications.
\end{abstract}

Keywords: monopolistic competition, monetary policy rule, pricing decisions, strategic complementarity, strategic substitutability.

JEL Classification: E52, C72.

\section{Introduction}

\footnotetext{
* This research was performed within the framework of the LABEX CORTEX (ANR-11-LABX-0042) of Universite de Lyon, within the program "Investissements d'Avenir" (ANR-11-IDEX-007) operated by the French National Research Agency (ANR) and funded by a joint grant from ANR and DFG. We thank Thomas Meissner, Emanuel Mönch, Stefan Sauer, Mike Woodford, the editor, Cesar Martinelli, an anonymous referee, and the participants of several research seminars and of the conference "Theory and Experiments in Monetary Economics 2018" for useful comments.

Camille Cornand - Université de Lyon, Lyon, F-69007, France ; CNRS, GATE Lyon Saint-Etienne, Ecully, F-69130, France; email: cornand@gate.cnrs.fr.

Frank Heinemann - Corresponding author - Technische Universität Berlin, Chair of Macroeconomics, H 52 - Straße des 17. Juni 135 - 10623 Berlin, Germany; Email: Frank.heinemann@tu-berlin.de.
} 
Strategies are complements [substitutes] if they can be ordered such that higher strategies by some players raise the incentives for other players to switch to higher [lower] strategies as well. Consequently, the best response functions are increasing [respectively decreasing]. ${ }^{1}$ According to the common wisdom, monopolistic competition generates a situation of strategic complementarity between price-setting firms: the optimal price charged by each single firm is increasing in the prices set by other firms, the intuition being that for each firm, higher prices of competing firms raise the demand for the firm's own product which provides an incentive for the firm to raise its own price: this is a relative price effect. This result is almost trivial in partial equilibrium models, but it is not necessarily true in general equilibrium models with endogenous aggregate demand. If the central bank responds to higher prices by raising the interest rate, higher prices of the firm's competitors also raise the aggregate price level and the interest rate, which reduces aggregate demand: this is the aggregate demand effect. If the aggregate demand effect exceeds the relative price effect, demand for the firm's own brand falls and the firm's best response is to lower its price. In this paper, we show that this happens in an economy with flexible prices when monetary policy follows the Taylor principle (Taylor, 1993). If nominal interest rates follow the Taylor principle, then the respective equilibrium is determinate and stable and inflation expectations are given by the target rate. Thus, changes in the current price level affect the real interest rate causing a sufficiently strong aggregate demand effect.

By its impact on the degree of strategic complementarity, the central bank can influence the adjustment process towards equilibrium after nominal demand shocks. If agents have imperfect information or if they are not perfectly rational, they cannot switch to a new equilibrium instantaneously after a shock, but need to explore the new equilibrium prices and eventually converge towards this new equilibrium. Whether prices are strategic complements or substitutes determines the characteristics of the adjustment process. In the experimental literature, it has been shown that when prices are complements, the aggregate price level moves slowly and individual actions are well-coordinated. Prices overshoot and approach the new equilibrium slowly. When prices are strategic substitutes, the average price level adjusts quickly, but individuals choose very different prices. They are poorly coordinated for a short time, but quickly coordinate on the new equilibrium. ${ }^{2}$ Thus, by affecting the degree of strategic complementarity, monetary policy also has an impact on the way that agents respond to shocks which in turn has real economic implications. Note that these adjustment processes towards a new equilibrium path come on top of gradual adjustments of the equilibrium path towards a steady state, where speed and real effects are caused by market frictions. Rational expectations equilibria of DSGE models abstract from strategic uncertainty. They cannot be used for discussing out-of-equilibrium behavior and, hence, they cannot explain adjustments towards equilibrium. Understanding how the monetary regime is related to strategic complementarities helps us filling this void. If we compare two economies, in which a shock raises prices in their respective equilibria by the same amount, one economy in which prices

\footnotetext{
${ }^{1}$ For a formal definition and more details, see Cooper and John (1988).

${ }^{2}$ We discuss these properties of adjustment processes in more detail in Section 4.
} 
are complements and one where they are substitutes, we may expect very distinct adjustment processes towards the new equilibrium that are also relevant for policy considerations.

While the New Keynesian literature of the 1980s usually assumed that pricing decisions are strategic complements, Woodford (2003, p. 160-173) documents that this needs not be the case in general equilibrium. ${ }^{3}$ The inclusion of sticky prices in otherwise standard RBC models with according calibrations implies that prices are strategic substitutes (Woodford, 2003, p. 165). However, Woodford (2003) also identifies three reasons why strategic complementarities may be higher than predicted by the standard model: specific (vs. common) factor markets (p. 166-167), non-constant elasticity of substitution between differentiated goods (p. 167-170) ${ }^{4}$, and the "economy's input-output structure"5, in particular the role of intermediate inputs (p. 170-172). Adam (2007) demonstrates that if monetary policy follows a strict nominal output target, it depends on the curvature of the utility function whether prices are strategic substitutes or complements.

In this paper, we provide an additional source for changes in the degree of strategic complementarity: in a standard monetary macro set-up with price-setting firms in monopolistic competition and without any frictions, we show that monetary policy can affect the degree of strategic complementarity and eventually turns prices from strategic complements into substitutes. The degree of strategic complementarity represents a monetary policy channel to which only very scarce attention has been attributed in the literature, in spite of its potentially strong policy implications. In a closely related paper, Bratsiotis (2007) shows that stronger responses of interest rates to the aggregate price level reduce strategic complementarity, while responses of interest rates to the output gap encourage strategic complementarity. He also provides parametric examples for policy rules that turn prices into substitutes. In this paper, we go a step further by showing that whether prices are substitutes or complements depends on whether monetary policy follows the Taylor principle or not.

Monetary policy is related to the degree of strategic complementarity between firms' pricing decisions, because it may respond to the aggregate price level. If monetary policy uses a Taylor-type feedback rule, we find that prices are strategic substitutes in the neighbourhood of the interior equilibrium at target inflation, provided that the coefficient by which the nominal interest rate responds to inflation guarantees determinacy of this equilibrium. When firms increase their prices, raising inflation above target, Taylor-type feedback rules raise the nominal interest rate, which lowers consumption demand. If determinacy guarantees constant inflation expectations, the real rate rises one-to-one with the nominal rate, and the aggregate demand effect is sufficiently strong to create an incentive for firms to reduce their prices. The Taylor principle, thus, turns prices into strategic substitutes rather than

\footnotetext{
${ }^{3}$ Woodford (2003, p. 161) defines strategic complementarities only for an exogenously given level of nominal demand. Thus, his examples are (at least) valid if monetary policy targets nominal output.

4 Preferences over differentiated goods of the Dixit-Stiglitz form assume a constant elasticity of substitution and imply a constant mark-up of prices over marginal costs. A relaxation of this assumption may affect the degree of strategic complementarity. See Kimball (1995) for further details.

${ }^{5}$ Woodford (2003, p. 170, referring to Basu (1995)). See Rotemberg and Woodford (1995) for further details.
} 
complements. By contrast, if the interest rate does not respond to changes in the price level as in a liquidity trap where monetary policy is restricted by the zero lower bound, pricing decisions remain strategic complements as in a partial equilibrium model without intertemporal substitution.

Indeterminate equilibria arise if interest rate responses to inflation violate the Taylor principle, but more generally, when price expectations move in the same direction as prices, so that the real interest rate is not affected by inflation. In these equilibria, prices are strategic complements because the aggregate demand effect is muted. This also holds for the nonstationary equilibria between the target steady state and the liquidity trap equilibrium. Here, deflation feeds into deflationary expectations and this spiral prevents a rise in today's demand if the price falls. We show that in the non-stationary and indeterminate rational expectations equilibria the demand effect is absent and, hence, prices are strategic complements.

For prices to be strategic substitutes, it is key that the expected real interest rate rises sufficiently strong for increasing prices to reduce aggregate demand. If the central bank has credibility for bringing inflation back to target so quickly that a present price increase raises expected inflation by less than nominal interest rates, the demand effect kicks in. The more the real rate responds to prices, the lower is the strategic complementarity of prices. For turning prices into substitutes, expected inflation must have a low variation as compared to the variance of nominal rates.

We discuss the policy implications of this finding. If we accept that equilibria do not fall from heaven but must be found by agents, the fact that a monetary policy rule turns complements into substitutes is particularly important, because the adjustment process of strategies towards equilibrium depends on whether strategies are complements or substitutes. Dynamic general equilibrium models describe the adjustment of prices to shocks along an equilibrium path. They do not answer the question whether and how firms will find this equilibrium path in a situation of strategic uncertainty. ${ }^{6}$ Experimental evidence (e.g. Assenza et al. (2014) and Heemeijer et al. (2009)) suggests that the speed of convergence and the stability of equilibrium are negatively related to the degree of strategic complementarity. Hence, a monetary policy obeying the Taylor principle speeds up the convergence process and contributes to stability not just because it yields a determinate equilibrium but also because it stabilizes the economy in case of shocks to agents' beliefs about other agents' actions.

By exploiting results from recent monetary policy experiments to derive theoretical policy implications, our paper contributes to a growing literature on experimental macroeconomics, as recently surveyed by Duffy (2016) and Arifovic and Duffy (2018). By providing the theoretical conditions under which monetary policy effectively turns a context of strategic complements into a context of strategic substitutes, our results complement the conclusion reached by Hommes (2018, p. 84), according to which "[t]he laboratory macro

\footnotetext{
${ }^{6}$ Recently, Farhi and Werning (2017) and Gabaix (2018) have introduced concepts of bounded rationality in DSGE models and demonstrated some of the consequences for the adjustment processes towards the steady state equilibrium after exogenous shocks.
} 
experiments also suggest an immediate way to stabilize the economy: policy can stabilize the economy by adding negative feedback to the system, or equivalently, by weakening the positive feedback." Our results can also rationalize why monetary policy is found to be effective in a variety of monetary policy experiments, like Assenza et al. (2013), Bao and Zong (2019), Pfajfar and Žakelj (2018), Hennequin and Hommes (2019), and Hommes et al. (2019).

The paper is structured as follows. Section 2 presents the economy. Section 3 introduces the monetary policy rules and shows how they affect the degree of strategic complementarities. Section 4 discusses the implications of this finding and Section 5 concludes.

\section{The economy}

In order to emphasize why monetary policy affects the degree of strategic complementarity, we use the simplest possible model that allows isolating this effect. ${ }^{7}$ Consider an economy derived from a general equilibrium model with flexible prices, populated by a representative household, a continuum of firms under monopolistic competition, and a central bank. Firms produce differentiated products and set prices facing individual demand functions that depend on their own price and on the aggregate price level. The central bank may use different types of rules that are introduced in Section 3.

\subsection{Representative household}

The representative household is infinitely lived and maximizes utility from consumption $C_{t}$ and labor $L_{t}$ in all periods according to the utility function: ${ }^{8}$

$$
\sum_{t=1}^{\infty} \beta^{t}\left(\frac{C_{t}^{1-\sigma}}{1-\sigma}-\frac{L_{t}^{1+\phi}}{1+\phi}\right)
$$

with $\sigma>0, \phi \geq 0$, and where $\beta \in[0,1]$ is the personal discount factor arising from time preference. The parameters $\sigma$ and $\phi$ govern the curvature of the utility function and are related to risk aversion. The representative household maximizes expected utility (1) from consumption and labor with the Dixit-Stiglitz consumption index for an infinite number of products $j \in[0,1]$,

$$
C_{t}=\left(\int_{0}^{1} C_{t}(j)^{\frac{\varepsilon-1}{\varepsilon}} d j\right)^{\frac{\varepsilon}{\varepsilon-1}},
$$

with the elasticity of substitution between goods $\varepsilon>1$. Households can save or borrow by holding positive or negative amounts of bonds. The stock of bonds at the start of period $t$ is denoted by $B_{t}$, which gives the household's budget constraint

\footnotetext{
${ }^{7}$ In particular, we do not insert shocks, as we do not need them for the basic argument.

${ }^{8}$ We follow the notation used in Galí (2008) and Faia (2008).
} 


$$
B_{t}+\Pi_{t}+W_{t} L_{t}-\int_{0}^{1} P_{t}(j) C_{t}(j) d j=\frac{B_{t+1}}{1+i_{t}},
$$

where $\Pi_{t}$ denotes profits, $W_{t} L_{t}$ is the wage income, $P_{t}(j)$ is the price of good $j$, and $i_{t}$ is the nominal interest rate in period $t$. Minimizing costs to achieve a given consumption level $C_{t}$ leads to the demand for good $j$,

$$
C_{t}(j)=\left(\frac{P_{t}(j)}{P_{t}}\right)^{-\varepsilon} C_{t}
$$

Equation (4) shows how the relation between demand for good $j$ and aggregate demand $C_{t}$ depends on the relative price of good $j$ vis-à-vis the aggregate price level $P_{t}$. The Dixit-Stiglitz price index $P_{t}$ is defined as

$$
P_{t}=\left(\int_{0}^{1} P_{t}(j)^{1-\varepsilon} d j\right)^{\frac{1}{1-\varepsilon}}
$$

From this, we get $\int_{0}^{1} P_{t}(j) C_{t}(j) d j=P_{t} C_{t}$, which simplifies the budget constraint. Thus, the intertemporal optimization problem of the household is represented by the Lagrangian:

$$
L=E_{0} \sum_{t=1}^{\infty} \beta^{t}\left(\frac{C_{t}^{1-\sigma}}{1-\sigma}-\frac{L_{t}^{1+\phi}}{1+\phi}\right)+\sum_{t=0}^{T} \lambda_{t} \beta^{t}\left[B_{t}+\Pi_{t}+W_{t} L_{t}-P_{t} C_{t}-\frac{B_{t+1}}{1+i_{t}}\right] .
$$

The first order conditions (leaving out the expectations operator) yield:

$$
\begin{aligned}
& C_{t}^{-\sigma}=\lambda_{t} P_{t}, \\
& L_{t}^{\phi}=\lambda_{t} W_{t}, \\
& \beta \lambda_{t+1}=\frac{1}{1+i_{t}} \lambda_{t},
\end{aligned}
$$

Equations (7) and (8) deliver a negative relation between labor supply and consumption demand

$$
L_{t}^{\phi}=C_{t}^{-\sigma} \frac{W_{t}}{P_{t}}
$$

Solving (7) for the Lagrange parameter and inserting it in (9) gives the Euler equation

$$
C_{t}^{-\sigma}=\left(1+i_{t}\right) \beta E_{0}\left(\frac{C_{t+1}^{-\sigma}}{P_{t+1}}\right) P_{t}=\beta E_{0}\left(\left(1+r_{t}\right) C_{t+1}^{-\sigma}\right),
$$

where $r_{t}$ is the real interest rate. The Euler equation defines consumption demand in period $t$ as a function of expected future inflation, future consumption and the current interest rate. Monetary policy can affect the current interest rate and expected future inflation by choosing how to respond to the current price level. Thereby, the price level affects current demand 
indirectly via its impact on the real interest rate - an effect that is absent in partial equilibrium models where aggregate demand is given exogenously.

\subsection{Firms}

Under monopolistic competition, each firm produces one differentiated good and acts as a price setter for its variety. Prices are flexible (i.e. firms can adjust prices each period). The production technology of firm $j$ is linear and given by

$$
Y_{t}(j)=L_{t}(j)
$$

where $Y_{t}(j)$ is the production output and $L_{t}(j)$ is labor input of firm $j$ at date $t$. The profit of firm $j$ is thus given by

$$
\Pi_{t}(j)=\left(P_{t}(j)-W_{t}\right) Y_{t}(j)
$$

Market clearing implies that production equals consumption, so that $Y_{t}(j)=C_{t}(j)$. Firms maximize profits by setting their own prices, taking the aggregate variables and demand function (4) as given,

$$
\max _{P_{t}(j)}\left(P_{t}(j)-W_{t}\right)\left(\frac{P_{t}(j)}{P_{t}}\right)^{-\varepsilon} C_{t} .
$$

Solving the first order condition for the firm's own price yields

$$
P_{t}(j)=\frac{\varepsilon}{\varepsilon-1} W_{t},
$$

where $\varepsilon /(\varepsilon-1)>1$ is the mark-up factor over marginal costs $W_{t}$. The best response function of firm $j$ with respect to prices of other firms is now hidden by the wage $W_{t}$ that depends on the aggregate price level via labor market clearing. ${ }^{9}$ Hence, we derive how $W_{t}$ depends on the prices charged by other firms. We are interested in the degree of strategic complementarity in a general equilibrium. Since equilibrium prices will be the same for all firms, we focus on the response to other firms' prices for the case where all other firms charge the same price.

\subsection{Labor Market}

Labor demand by firm $j$ is

$$
L_{t}(j)=Y_{t}(j)=C_{t}(j)=C_{t}\left(\frac{P_{t}(j)}{P_{t}}\right)^{-\varepsilon},
$$

\footnotetext{
${ }^{9}$ This is why it makes such a big difference of whether one assumes common or specific labor markets as noted by Woodford (2003).
} 
and aggregate labor demand is given by

$$
L_{t}=\int_{0}^{1} L_{t}(j) d j=C_{t} \int_{0}^{1}\left(\frac{P_{t}(j)}{P_{t}}\right)^{-\varepsilon} d j .
$$

Setting aggregate labor demand equal to labor supply, implicitly given by (10), and solving the equation for the wage level yields

$$
W_{t}=P_{t}\left(\int_{0}^{1}\left(\frac{P_{t}(j)}{P_{t}}\right)^{-\varepsilon} d j\right)^{\phi} C_{t}^{\phi+\sigma} .
$$

If almost all firms charge the same price, the expression simplifies to

$$
W_{t}=P_{t} C_{t}^{\phi+\sigma}
$$

Inserting (17') into (14) yields

$$
P_{t}(j)=\frac{\varepsilon}{\varepsilon-1} P_{t} C_{t}^{\phi+\sigma} .
$$

Replacing $C_{t}$ by the Euler equation (11) gives

$$
\begin{aligned}
& P_{t}(j)=\frac{\varepsilon}{\varepsilon-1} P_{t}\left[\left(1+i_{t}\right) \beta E_{t}\left(\frac{C_{t+1}^{-\sigma}}{P_{t+1}}\right) P_{t}\right]^{\frac{-(\phi+\sigma)}{\sigma}} \\
& =\frac{\varepsilon}{\varepsilon-1} P_{t}\left[\left(1+i_{t}\right) \beta E_{t}\left(\frac{C_{t+1}^{-\sigma}}{1+\pi_{t+1}}\right)\right]^{\frac{-(\phi+\sigma)}{\sigma}}=\frac{\varepsilon}{\varepsilon-1} P_{t}\left[\beta E_{t}\left(\left(1+r_{t}\right) C_{t+1}^{-\sigma}\right)\right]^{-(\phi+\sigma)}
\end{aligned}
$$

Equation (19) describes the best response function for firm $j$ with respect to the aggregate price level for a given real interest rate and for given expectations of future consumption. It, thus, represents a partial equilibrium approach without intertemporal substitution and implies strategic complements, as the best response function is increasing, $\partial P_{t}(j) / \partial P>0$.

\section{Central bank's monetary policy rule}

The standard approach in dynamic general equilibrium models is to close the model by a monetary policy rule, assuming rational expectations and imposing a transversality condition. The central bank may use different types of rules. As a benchmark case, we start by presenting nominal output targeting, as studied by Adam (2007). In this case, whether prices are strategic complements or substitutes depends on parameter values of the utility function. We then study feedback (Taylor-type) policy rules by which interest rates respond to inflation. Here, the parameters of this policy function affect the degree of strategic complementarity as shown by Bratsiotis (2007) and determine whether prices are strategic complements or substitutes independently from the parameters of the utility function. We establish that prices are strategic substitutes whenever the equilibrium is determinate. 


\subsection{Nominal output targeting}

Suppose that the central bank controls nominal demand $P_{t} C_{t}=\bar{Y}$. Then (18) becomes

$$
P_{t}(j)=\frac{\varepsilon}{\varepsilon-1} \bar{Y} C_{t}^{\phi+\sigma-1}
$$

Note that nominal output targeting implies that real demand, $C_{t}=\bar{Y} / P_{t}$, depends negatively on $P_{t}$. Thus, the slope of the best response function

$$
\frac{\partial P_{t}(j)}{\partial P_{t}}=\frac{\varepsilon}{\varepsilon-1} \bar{Y}(\phi+\sigma-1) C_{t}^{\phi+\sigma-2} \frac{\partial C_{t}}{\partial P_{t}}
$$

is positive if and only if $\sigma+\phi<1$. So, here we get strategic complementarity depending on $\sigma+\phi$, as in Adam (2007). ${ }^{10}$

Proposition 1 (Adam, 2007): If the central bank implements a nominal output targeting rule, prices are strategic complements if $\sigma+\phi<1$ and strategic substitutes if $\sigma+\phi>1$.

Under nominal output targeting, the equilibrium and the best response function in period $t$ are independent from expectations about future prices and consumption, because the central bank does not affect private decisions on the intertemporal allocation via an interest-rate policy, but rather fixes contemporaneous (nominal) output directly. Marginal costs, however, depend on the price level. Using $C_{t}=\bar{Y} / P_{t}$, equation (17') turns into $W_{t}=\bar{Y} P_{t}^{1-\phi-\sigma}$. Thus, for $\sigma+\phi<1$, marginal costs are increasing in the price level. If other firms increase their price, marginal costs for firm $i$ are rising which induces a higher optimal price for firm $i$. So here, prices are strategic complements. The reverse causality holds for $\sigma+\phi>1$. For $\sigma+\phi=1$, marginal costs do not depend on the price level and equation (20) turns into $P_{t}(j)=\varepsilon /(\varepsilon-1) \cdot \bar{Y}$, i.e. the optimal price is (locally) independent of the prices set by other firms.

\subsection{The Taylor principle and strategic substitutability}

We now assume that the central bank implements a feedback rule for the interest rate (Taylortype rule):

$$
i_{t}=\bar{i}+\delta\left(\pi_{t}-\pi^{*}\right),
$$

where $\pi_{t}=P_{t} / P_{t-1}-1 . \pi^{*}$ is the inflation target and $\delta$ is the strength of the policy reaction to deviations of inflation from the target. Parameter $\bar{i}$ is the nominal interest rate that results from target inflation and the natural real interest rate, denoted by $\bar{r}$, i.e.

$$
1+\bar{i}=(1+\bar{r})\left(1+\pi^{*}\right) \text {. }
$$

\footnotetext{
${ }^{10}$ Adam (2007, p. 272) defines a parameter $\xi$ that equals $\sigma+\phi$ for our utility function.
} 
If the interest rate responds to inflation with a coefficient $\delta>1+\bar{r}$ (Taylor principle), the steady state is the only equilibrium consistent with the transversality condition and determines expected future inflation at the target rate $\pi^{*}{ }^{11}$ Note that this standard approach requires a feedback rule that does not account for the zero lower bound on interest rates. We will use this as a benchmark and consider the zero lower bound in Section 3.3 below. Since prices are assumed to be flexible, expected future consumption is not affected by today's price level. Inserting the policy rule (21) into (19), gives the best response function of firm $j$ 's prices with respect to the aggregate price level:

$$
P_{t}(j)=\frac{\varepsilon}{\varepsilon-1} P_{t}\left[\left(1+\bar{i}+\delta\left(\frac{P_{t}}{P_{t-1}}-1-\pi^{*}\right)\right) \beta \frac{E_{t} C_{t+1}^{-\sigma}}{1+\pi^{*}}\right]^{\frac{-(\phi+\sigma)}{\sigma}} .
$$

This functional form is valid only locally around the equilibrium. It implies

$$
\begin{aligned}
\frac{\partial P_{t}(j)}{\partial P_{t}}= & \frac{\varepsilon}{\varepsilon-1}\left[\left(1+\bar{i}+\delta\left(\frac{P_{t}}{P_{t-1}}-1-\pi^{*}\right)\right) \beta \frac{E_{t} C_{t+1}^{-\sigma}}{1+\pi^{*}}\right]^{\frac{-(\phi+\sigma)}{\sigma}} \\
& -\frac{(\phi+\sigma)}{\sigma} \cdot \frac{\varepsilon}{\varepsilon-1} P_{t}\left[\left(1+\bar{i}+\delta\left(\frac{P_{t}}{P_{t-1}}-1-\pi^{*}\right)\right) \beta \frac{E_{t} C_{t+1}^{-\sigma}}{1+\pi^{*}}\right]^{\frac{-(\phi+2 \sigma)}{\sigma}} \cdot \beta \frac{E_{t} C_{t+1}^{-\sigma}}{1+\pi^{*}} \cdot \delta \frac{1}{P_{t-1}} \\
= & \frac{\varepsilon}{\varepsilon-1}\left[\left(1+i_{t}\right) \beta \frac{E_{t} C_{t+1}^{-\sigma}}{1+\pi^{*}}\right]^{\frac{-(\phi+\sigma)}{\sigma}} \cdot\left[1-\frac{\phi+\sigma}{\sigma} P_{t}\left(\left(1+i_{t}\right) \beta \frac{E_{t} C_{t+1}^{-\sigma}}{1+\pi^{*}}\right)^{-1} \cdot \beta \frac{E_{t} C_{t+1}^{-\sigma}}{1+\pi^{*}} \cdot \delta \frac{1}{P_{t-1}}\right] \\
= & \frac{\varepsilon}{\varepsilon-1}\left[\left(1+i_{t}\right) \beta \frac{E_{t} C_{t+1}^{-\sigma}}{1+\pi^{*}}\right]^{\frac{-(\phi+\sigma)}{\sigma}} \cdot\left[1-\frac{(\phi+\sigma) \delta}{\sigma} \cdot \frac{1+\pi_{t}}{1+i_{t}}\right] .
\end{aligned}
$$

Apparently, the derivative gets smaller if $\delta$ rises. The larger $\delta$, the more does the interest rate respond to inflation, which implies a larger change in aggregate demand. Thus, a more aggressive response of interest rates to inflation reduces the degree of strategic complementarity by strengthening the aggregate demand effect. The derivative (24) is positive if and only if

$$
\begin{aligned}
& \delta \frac{\phi+\sigma}{\sigma}\left(1+\pi_{t}\right)<1+i_{t}=1+\bar{i}+\delta\left(\pi_{t}-\pi^{*}\right) \\
\Leftrightarrow & \delta\left(\frac{\phi+\sigma}{\sigma}\left(1+\pi_{t}\right)-\pi_{t}+\pi^{*}\right)<1+\bar{i}
\end{aligned}
$$

\footnotetext{
${ }^{11}$ See Woodford (2003, Chapter 2, p. 91). The fact that we have $\delta>1+\bar{r}$ instead of the usual $\delta>1$ stems from our renouncement of log-linear approximations. See Appendix A for more details.
} 


$$
\begin{aligned}
& \Leftrightarrow \delta\left(\frac{\phi}{\sigma}\left(1+\pi_{t}\right)+1+\pi^{*}\right)<1+\bar{i} \\
& \Leftrightarrow \delta<(1+\bar{i})\left(\frac{\phi}{\sigma}\left(1+\pi_{t}\right)+1+\pi^{*}\right)^{-1} .
\end{aligned}
$$

Thus, prices are strategic complements if and only if the feedback parameter $\delta$ is sufficiently small compared to the right-hand side of (25). Otherwise prices are strategic substitutes. Suppose that the current rate of inflation is close to the target rate $\pi^{*}$, as is the case in a steady state equilibrium. Then, (25) becomes

$$
\delta<\frac{\sigma}{\phi+\sigma} \cdot \frac{1+\bar{i}}{1+\pi^{*}}=\frac{\sigma}{\phi+\sigma} \cdot(1+\bar{r}) .
$$

Thus, for any $\delta>1+\bar{r}$, we get strategic substitutes, because $\frac{\sigma}{\phi+\sigma}<1$ and, thus, $\delta>1+\bar{r}$ implies that inequality (26) is reversed.

Proposition 2: If the central bank implements a feedback rule for the interest rate such that $\delta>1+\bar{r}$, firms' best response functions are decreasing around the steady-state equilibrium. Thus, in equilibrium, prices are strategic substitutes.

The central bank, via its stabilization policy, turns prices into strategic substitutes. Taylor-type monetary policy rules are related to the degree of strategic complementarity between firms' pricing decisions, because monetary policy responds to the aggregate price level. When monopolistic competitive firms increase their price, they generate inflation, which implies a higher interest rate set by the central bank via its monetary policy rule. Increasing the interest rate reduces consumption demand. This reduction in consumption gives an incentive for profit-maximizing firms to reduce their prices. In normal times, the monetary policy rule thus induces a decrease in the degree of strategic complementarities among firms' pricing decisions and even turns actions into substitutes rather than complements if the effect on demand is sufficiently strong. The impact of prices on the interest rate that yields strategic substitutability is not a razor's edge case, but is instead robust with respect to different parameter calibrations. Notice, however, that such a result may not hold when monetary policy does not affect the interest rate, as in the liquidity trap, as we explain next.

\subsection{The zero lower bound and strategic complementarity}

The Taylor rule (21) does not account for the zero lower bound on interest rates. As in most dynamic general equilibrium models, it should, therefore, only be considered for inflation rates sufficiently close to or above the steady state. If inflation becomes very small, in particular negative, monetary policy cannot respond with the same linear rule to current prices, because negative interest rates would allow for arbitrage profits. We account for this by extending the monetary policy rule such that 


$$
i_{t}=\left\{\begin{array}{cc}
\bar{i}+\delta\left(\pi_{t}-\pi^{*}\right) & \text { if } \\
0 & \text { otherwise. }
\end{array} \pi_{t}>\pi^{*}-\bar{i} / \delta\right.
$$

This also affects the slope of a firm's best response function with respect to the aggregate price level. If $\pi_{t}<\pi^{*}-\bar{i} / \delta$, the interest rate is bounded at zero and equation (19) turns to

$$
P_{t}(j)=\frac{\varepsilon}{\varepsilon-1} P_{t}\left[\beta E_{t}\left(\frac{C_{t+1}^{-\sigma}}{P_{t+1}}\right) P_{t}\right]^{\frac{-(\phi+\sigma)}{\sigma}} .
$$

Due to the stability of the liquidity-trap equilibrium in dynamic general equilibrium models, ${ }^{12}$ we may replace expected future inflation with the inflation rate in the liquidity trap $\pi^{L}<\pi^{*}$. This yields the best response function

$$
P_{t}(j)=\frac{\varepsilon}{\varepsilon-1} P_{t}\left[\beta \frac{E_{t} C_{t+1}^{-\sigma}}{1+\pi^{L}}\right]^{\frac{-(\phi+\sigma)}{\sigma}}=\frac{\varepsilon}{\varepsilon-1} P_{t}\left[\frac{1+\pi^{L}}{\beta}\right]^{\frac{\phi+\sigma}{\sigma}} E_{t} C_{t+1}^{\phi+\sigma} .
$$

Once more, the functional form is valid only locally around the (liquidity trap) equilibrium. It implies

$$
\frac{\partial P_{t}(j)}{\partial P_{t}}=\frac{\varepsilon}{\varepsilon-1}\left[\beta \frac{E_{t} C_{t+1}^{-\sigma}}{1+\pi^{L}}\right]^{\frac{-(\phi+2 \sigma)}{\sigma}}=\frac{\varepsilon}{\varepsilon-1}\left[\frac{1+\pi^{L}}{\beta}\right]^{\frac{\phi+\sigma}{\sigma}} E_{t} C_{t+1}^{\phi+\sigma}>0 .
$$

Thus, prices are strategic complements if the economy is stuck in a liquidity trap.

Proposition 3: In the liquidity trap, prices are strategic complements.

In a liquidity trap, neither the interest rate nor future expected inflation are affected by small changes in the current rate of inflation. Thus, small changes of other firms' prices have no impact on the intertemporal substitution and, thus, pricing decisions are strategic complements as in a partial equilibrium model.

\subsection{Indeterminate equilibria and strategic complementarity}

With a coefficient $\delta<1+\bar{r}$, the equilibrium is indeterminate if the central bank follows feedback rule (21)..$^{13}$ A pure interest rate peg is a special case of this with $\delta=0$. Even though different paths of inflation rates may be an equilibrium in such an economy, we may still evaluate the firms' best response function in such an equilibrium.

Combining the Fisher equation,

$$
\left(1+i_{t}\right) /\left(1+r_{t}\right)=1+E_{t}\left(\pi_{t+1}\right)
$$

with feedback rule (21) yields

\footnotetext{
${ }^{12}$ See, e.g., Benhabib, Schmidt-Grohe and Uribe (2002, p. 544): the steady-state is such that the inflation rate is constant.

${ }^{13}$ See Appendix A for details.
} 


$$
1+E_{t}\left(\pi_{t+1}\right)=\frac{1+\bar{i}+\delta\left(\pi_{t}-\pi^{*}\right)}{1+r_{t}}
$$

Along any equilibrium path, $r_{t}=\bar{r}$ for all $t$. Hence,

$$
E_{t}\left(\pi_{t+1}\right)=f\left(\pi_{t}\right)=\frac{\bar{i}-\bar{r}+\delta\left(\pi_{t}-\pi^{*}\right)}{1+\bar{r}} .
$$

Because $f^{\prime}<1$, any price path with $\pi_{t+1}=f\left(\pi_{t}\right)$ is a rational expectations equilibrium. Here, a change in current inflation also affects expected future inflation, while for $\delta>1+\bar{r}$, the rational expectations equilibrium is determinate and associated with an expected inflation rate of $\pi^{*}$ independent of current inflation.

Inserting (32) together with policy rule (21) into Equation (19), gives the best response function of firm $j$ 's price with respect to $P_{t}$ in this particular equilibrium:

$$
\begin{aligned}
P_{t}(j) & =\frac{\varepsilon}{\varepsilon-1} P_{t}\left[\left(1+\bar{i}+\delta\left(\pi_{t}-\pi^{*}\right)\right) \beta E_{t}\left(\frac{C_{t+1}^{-\sigma}}{\left.1+f\left(\pi_{t}\right)\right)}\right)\right]^{\frac{-(\phi+\sigma)}{\sigma}} \\
& =\frac{\varepsilon}{\varepsilon-1} P_{t}\left[\left(1+\bar{i}+\delta\left(\pi_{t}-\pi^{*}\right)\right) \beta E_{t}\left(\frac{(1+\bar{r}) C_{t+1}^{-\sigma}}{1+\bar{i}+\delta\left(\pi_{t}-\pi^{*}\right)}\right)\right]^{\frac{-(\phi+\sigma)}{\sigma}} \\
& =\frac{\varepsilon}{\varepsilon-1} P_{t}\left[\beta(1+\bar{r}) E_{t}\left(C_{t+1}^{-\sigma}\right)\right]^{-(\phi+\sigma)}
\end{aligned}
$$

As $f^{\prime}>0$, an increase in current inflation leads to an increase in inflationary expectations. Higher expected future prices increase current demand and work against the demand reduction coming from higher nominal interest rates. Around an equilibrium, the best response function is increasing as in a partial equilibrium or in the case of the zero-lower bound and, hence, prices are strategic complements. The reason is that in any rational expectations equilibrium, for $\delta<1+\bar{r}$, the effects of a marginal change in the current price level on nominal interest rate and expected future inflation offset each other, so that the real interest rate stays constant and aggregate demand is independent from the current price level. ${ }^{14}$

Proposition 4: When monetary policy follows a Taylor-type rule with $\delta<1+\bar{r}$, prices are strategic complements in any equilibrium.

Note that the same logic also applies to any non-stationary equilibrium for $\delta>1+\bar{r}$. As we know from Benhabib, Schmidt-Grohé and Uribe (2002), the zero lower bound on interest rates leads to two steady states and a continuum of non-stationary equilibria with starting values anywhere between these steady states. In these non-stationary equilibria, we have

\footnotetext{
${ }^{14}$ The relationship between determinacy and substitutability can also be shown with a log-linear approximation of the model. For more details, see Appendix B.
} 


$$
E_{t}\left(\pi_{t+1}\right)=\left\{\begin{array}{ccc}
f\left(\pi_{t}\right) & \text { if } & i_{t}>0 \\
\pi_{L} & \text { if } & i_{t}=0
\end{array} .\right.
$$

In the first case, the aggregate demand effect is silenced, because an increase in the current price level raises future inflation by the same amount as nominal interest rates. Here, we get the same results as for $\delta<1+\bar{r}$. The second case arises when the economy falls into the zerolower bound and is treated in Section 3.3. In both cases, the real interest rate is not affected by changes in the aggregate price level and, hence, the aggregate demand effect is absent, leaving us with the relative price effect for which prices are strategic complements.

These considerations require that the economy follows a rational expectations equilibrium. Of course, equilibrium indeterminacy casts serious doubts on this prerequisite. If expectations are not rational, then prices may be substitutes or complements, depending on how the current rate of inflation affects expected future inflation.

\subsection{Interpretation}

In this section, we discuss the logic behind the results that we obtained in Section 3. This allows drawing further conclusions about the degree of strategic complementarity during different phases of an economy and how it is affected by monetary policy.

Whether prices are strategic substitutes or complements, depends on how current inflation affects demand via the Euler equation. Replacing aggregate demand $C_{t}$ by the Euler equation, the best response function becomes

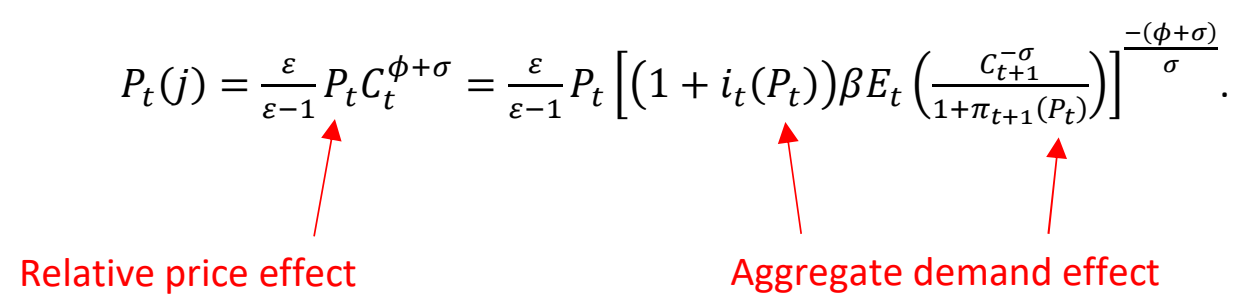

The best response function displays two effects: the relative price effect and the aggregate demand effect. The relative price effect comes from substitutability of products and reflects the partial-equilibrium view. The aggregate demand effect arises from the Euler equation via two channels: current prices may affect the interest rate (interest rate channel) and expected future inflation (inflation expectation channel). Higher interest rates make future goods relatively cheaper and reduce current demand, higher expected future prices have the opposite effect.

The aggregate demand effect is purely driven by expectations. Agents consume less today if they expect to get more goods tomorrow for the same amount of today's money. If the expected real interest rate rises in response to a price increase, the demand effect works against the price effect and reduces strategic complementarities. For prices to become strategic substitutes, the demand effect must be sufficiently strong. This requires a strong response of the expected real rate on price changes that can be obtained by strong responses of the nominal rate and weak responses of expected inflation. 
For determinate equilibria, expected inflation is fixed and current prices affect demand only via the interest rate channel. Determinacy of the steady state at target inflation requires that interest rates respond so strongly to current inflation that the aggregate demand effect dominates the relative price effect.

At the zero lower bound, neither the interest rate $i_{t}$ nor the expected inflation respond to current prices. The real rate is exogenously given and the aggregate demand effect is absent. Here, best responses are given by the relative price effect as in partial equilibrium, which implies that prices are strategic complements. Note that this does not hinge on price expectations being given by $\pi_{L}$. If agents would believe in the target rate $\pi^{*}$, we would see no demand effect either.

Suppose that expectations respond to current inflation. To escape the liquidity trap, the central bank has to keep interest rates low for some time, when inflation starts rising. If expected inflation is responding positively on current inflation, higher prices increase current demand and the demand effect works in the same direction as the aggregate price effect. An increase in today's prices raises inflation expectations, lowers the real interest rate, and stimulates demand. On such an escape trail, the demand effect works in the same direction as the relative price effect and strategic complementarities are even higher than in the respective partial equilibrium.

For indeterminate and non-stationary equilibria, expected inflation responds one-toone with nominal interest rate. Here, the two channels of the demand effect cancel each other. The real rate is exogenously given and, thus, there is no aggregate demand effect, implying that prices are strategic complements as in the partial equilibrium.

Note that if the central bank violates the Taylor principle, it may affect inflation expectations by communication and other strategies that are also related to the bank's credibility. As we have multiple equilibria for such a policy, equilibrium selection is a subtle issue and expectations may be self-fulfilling. The better the central bank anchors inflation expectations, the smaller is the interest rate response that is required to achieve the desired demand effect. The higher the stability of inflation expectations, the lower are strategic complementarities.

\section{Implications}

In this paper, we have shown how monetary policy affects the degree of strategic complementarity between firms' pricing decisions in the neighbourhoods of the respective rational expectations equilibria. Interest-rate responses to current inflation reduce the degree of strategic complementarity. If monetary policy follows the Taylor principle, it turns prices into strategic substitutes. By contrast, in a liquidity trap where monetary policy is restricted by the zero lower bound, pricing decisions are strategic complements.

The degree of strategic complementarity does not directly change the equilibrium path, but it has important implications for the speed of convergence to equilibrium after a 
shock, for the effectiveness of policy measures, for the stability of the economy in response to belief shocks, and for the welfare effects of transparency. Here, we want to summarize these implications.

\subsection{Adjustments processes towards equilibrium and the real effects of monetary policy}

While the effects analysed by DSGE models occur on the equilibrium path, DSGE models do not answer the question whether and how firms will find the equilibrium in a situation of strategic uncertainty. Experiments teach us that the degree of strategic complementarity also relates to the adjustment of individual actions towards the equilibrium after a shock. Moreover, they also teach us that real effects may emerge from the adjustment process towards the new equilibrium. ${ }^{15}$ We discuss the implications of our findings in terms of convergence towards equilibrium and economic policy in light of the experimental evidence.

Consider an economy in equilibrium that is hit by a shock that demands price changes by firms to stay in equilibrium. Assume that firms have limited or asymmetric information so that they do not immediately find the new full-information equilibrium. If prices are strategic substitutes, any deviation of the general price level from the new full-information equilibrium in one direction incentivises firms to deviate in the other. If prices are above equilibrium, firms have an incentive to reduce their prices below the equilibrium and vice versa. Thus, prices quickly converge to equilibrium. By contrast, if prices are strategic complements, deviations of the general price level provide incentives to deviate in the same direction. Deviations reinforce each other. If prices are above equilibrium, firms who have set prices at or below equilibrium have an incentive to raise their prices above equilibrium and those who set prices above equilibrium already, will stay above the equilibrium as well, even if they get better information and adjust towards the equilibrium value. The average may rise for some time and induce agents to extrapolate the direction of change. Thus, we may expect a considerable overshooting of prices after a shock if prices are strategic complements.

Whether and how fast agents find a new equilibrium after a shock is an empirical question, because rational expectations models assume that agents jump towards the new equilibrium. In these models, history dependence is obtained by adding frictions to the adjustment process (e.g. sticky prices or sticky information) that eventually smooth the equilibrium path towards the new steady state.

Experimental evidence suggests that different adjustment processes are at work depending on whether the environment is characterized by strategic substitutability or strategic complementarity. Fehr and Tyran (2005) summarize evidence on the adjustment processes driven by subjects in laboratory experiments. "Under strategic complementarity, a small amount of individual irrationality may lead to large deviations from the aggregate predictions of rational models; under strategic substitutability, a minority of rational agents may suffice to generate aggregate outcomes consistent with the predictions of rational

\footnotetext{
${ }^{15}$ Real effects of monetary policy may arise in equilibrium of a model with sticky prices or sticky information, but real effects also arise in the process of convergence towards the equilibrium of an otherwise frictionless economy. Bounded rationality may be viewed at as a friction in the adjustment of expectations.
} 
models. Thus, the presence of strategic substitutability or complementarity seems to be a key condition in determining when a population that is heterogeneous with regard to rationality reaches either a "rational" or an "irrational" outcome" (Fehr and Tyran, 2005, p. 44). Under strategic complementarity even many players who are capable of calculating the new equilibrium, will not act accordingly, because they expect others to deviate. ${ }^{16}$ If a significant fraction of players is expected to have adaptive expectations, the best response leads to a slow adjustment towards a new equilibrium under complementarity, but leads to a temporary overshooting of actions and quick adjustment to the new equilibrium under substitutes. Fehr and Tyran (2008) report that in their experiment twice as many subjects expect equilibrium prices under substitutability than under complementarity. Thus, players also seem to expect a faster convergence and behave as if they attribute more rationality to other players.

Hommes (2011) and Assenza et al. (2014) survey learning-to-forecast experiments. In these experiments, participating subjects forecast prices, while the realized price depends on the average forecast. In a positive (negative) feedback system, an increase in the average forecast leads to an increase (a decrease) in the market price. ${ }^{17} \mathrm{~A}$ main conclusion of this literature is that after a shock, subjects learn the new rational equilibrium rather fast in the negative feedback system, while it takes subjects much longer to learn it in the positive feedback system.

Figure 1. Adjustment processes under strategic complements and substitutes
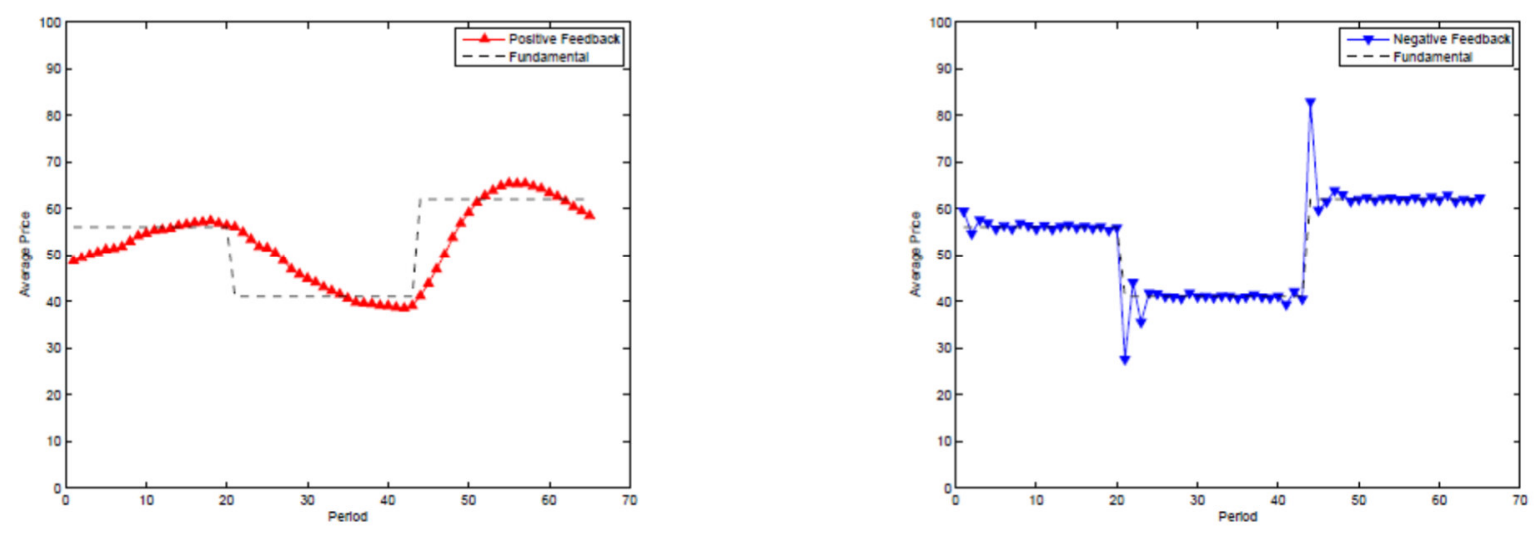

\footnotetext{
16 Haltiwanger and Waldman (1989) present a model in which strategic complementarities induce naïve agents to have a disproportionate impact on equilibrium outcomes in comparison to those who form rational expectations.

${ }_{17}$ Note here that a negative feedback system exactly corresponds to a situation in which stated expectations are strategic substitutes, while a positive feedback system to a situation in which stated expectations are strategic complements.
} 

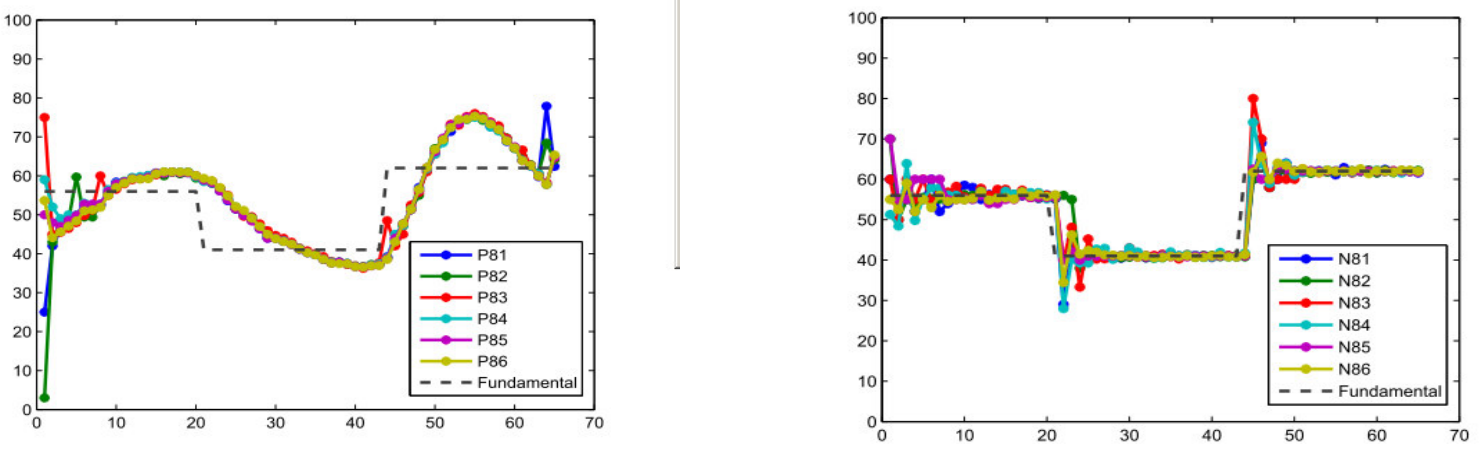

Notes on Figure 1: strategic complements (left panels) and substitutes (right panels). The upper graphs show the average expected price, lower graphs show subjects' individual expectations. Source: Assenza et al. (2014), p 32.

Figure 1 (taken from Assenza et al. (2014) and based on Bao et al. (2012)) presents an example of an experiment in which subjects adjust their price forecasts to shocks. In each economy, 6 subjects repeatedly submit price-level forecasts. Each period, the computer generates realized prices based on a DSGE model in which distinct producers set their prices based on distinct subjects' forecasts. In the positive feedback system, $d P_{i} / d P=20 / 21$, in the negative feedback system, $d P_{i} / d P=-20 / 21$. These may be high degrees of strategic complementarity and substitutability as compared to a macro-economy, but they clarify the distinct patterns of adjustment processes. The figures show average prices in the upper panel and individual price forecasts in the lower panel. There are two shocks in Periods 20 and 43 . The equilibrium path is represented by the broken line and it is the same for both economies.

In the case of strategic complements (left panel), the adjustment process is cyclical with waves building up that overshoot the new equilibrium before price adjustments change direction. Subjects seem to interpolate past price changes for their forecasts. Thus, it needs an overshooting until they realize that they should reverse their adjustments. The lower graph shows that individual expectations are very well coordinated (except for the initial periods). Shocks have no big impact on the degree of coordination.

In the case of strategic substitutability or negative feedback (right panel), fast convergence to a new equilibrium is observed. Shocks have large immediate effects and may even lead to a temporary overshooting of expectations. The lower graph shows that individual expectations are poorly coordinated during the first periods after each shock. But, the average price level adjusts quickly to the new equilibrium and once that is reached, subjects are also well coordinated. In this environment, the theoretical swing described by the rational expectation equilibrium suitably accounts for the observations except for the first few periods after a shock.

If one compares the adjustment processes across different groups of subjects from the same experiment, the aforementioned characteristics are observed regularly. The amount of overshooting and mis-coordination in the case of substitutes varies between groups. Under complements, the lengths and amplitude of waves varies. This has consequences for 
predictability. In an economy with strategic substitutes, the equilibrium gives a reliable prediction for medium- and long-term adjustment. Short-term predictions, however, are difficult and unreliable. Under strategic complements, the opposite is true. Shocks have small immediate effects and price changes are gradual, so that short-run predictions can be made rather accurately. But if the length of waves and overshooting is unpredictable, then mediumand long-term forecasts are unreliable.

Experimental evidence suggests that the speed of convergence and the stability of equilibria are negatively related to the degree of strategic complementarity. In the light of our results, a monetary policy that follows the Taylor principle leads to strategic substitutability, speeds up the convergence process towards equilibrium, and allows good medium-term forecasts at the expense of temporary mis-coordination and only small real effects. Thus, the Taylor principle contributes to stability not just because it yields a determinate equilibrium but also, because it stabilizes the economy from shocks to agents' beliefs about other agents' actions.

If monetary policy chooses milder responses to inflation or if the economy is stuck in the liquidity trap, prices are strategic complements and nominal spending shocks have small immediate price effects, allowing for larger real effects. The adjustment towards the new equilibrium is slow and medium-term forecasts are unreliable. This also burdens the central bank that might wish to use its forecasting reputation to guide the economy out of a liquidity trap. With medium- and long-term forecasts being unreliable, forward guidance lacks the credibility that it requires to be effective.

\subsection{Optimal transparency}

Our results also provide some new insights on the optimal communication strategy of central banks. We know from the coordination games literature in the vein of Morris and Shin (2002) and their applications to macroeconomics by e.g. Angeletos, lovino and La'O (2016), Angeletos and La'O (2019), and Lorenzoni $(2009,2010)$ that the degree of strategic complementarities impacts the welfare effects of public signals.

As pointed out by Angeletos and Pavan (2007), whether a commitment to disclose central bank information raises or reduces expected welfare depends crucially on whether the equilibrium degree of coordination is below or above the efficient degree of coordination. In the Morris and Shin (2002) benchmark case where coordination does not matter at the social level, transparency (i.e. an increase in the precision of public information) reduces welfare. By contrast, in micro-founded macro-applications, where coordination enters social welfare in the same extent as fundamentals do, transparency is always beneficial. For any welfare function in between these two extremes, transparency may be detrimental, if prices are strategic complements. In a situation of strategic substitutability, instead, public announcements are generally beneficial, because agents are less responsive to them and, thus, any piece of additional public information helps agents to predict the fundamentals and take decisions that are closer to a full-information equilibrium. 
While it is usually believed that macro environments are characterized by strategic complementarities, especially under monopolistic competition, we show that with a monetary policy obeying the Taylor principle, this is not likely to be true. If the central bank interest rate responds to the price level with a sufficiently large weight, prices are strategic substitutes and transparency is beneficial for expected welfare.

If the coefficient by which the interest rate responds to prices is rather small, as in a liquidity trap, transparency may be harmful. This implies different communication strategies, depending on the economic situation. While the literature has usually dealt with transparency policy issues as unconditional settings of the precision of public signals, our findings call for a differentiated communication policy for central banks depending on whether the economy is in a liquidity trap or not.

\section{Conclusion}

In this paper, we have shown how monetary policy affects the degree of strategic complementarity between firms' pricing decisions. Interest-rate responses to current inflation reduce the degree of strategic complementarity. If monetary policy follows the Taylor principle, it turns prices into strategic substitutes. By contrast, in a liquidity trap where monetary policy is restricted by the zero lower bound, pricing decisions are strategic complements. We have discussed the implications of the degree of strategic complementarity for the adjustment process and speed of convergence to equilibrium after a shock and the real effects of monetary policy: when prices are strategic complements (substitutes), the adjustment process is rather slow (fast) and the real effects of monetary policy are high (low).

While we have discussed the real effects of monetary policy that may arise in the adjustment process towards equilibrium, our analysis has abstracted from standard frictions, such as sticky prices or sticky information. We leave these avenues to further research, but shortly discuss the potential implications of our results in terms of the adjustment to shocks, for the stability of the economy in response to belief shocks and for the welfare effects of transparency.

In an economy with frictions, interest-rate responses to inflation have the same qualitative impact on aggregate demand as in the frictionless economy analyzed in this paper. Thus, the degree of strategic complementarity is reduced by stronger responses of real interest rates to the price level. In an economy with sticky prices, the degree of strategic complementarity determines the real effectiveness of monetary policy on the equilibrium path (Woodford, 2003). Strategic complementarities in pricing decisions result in strong inertia after a shock with large real effects of monetary policy, while the economy rapidly adjusts to a new equilibrium if prices are strategic substitutes. In a context with strategic complementarities, firms have a relatively high incentive to coordinate their prices. If others are unable to change prices, it may be optimal for those who can adjust their prices not to do 
so because they expect others will not. By contrast, if prices are strategic substitutes, firms have an incentive to change their prices even more if others cannot do it. This increases price dispersion for a while, but keeps the average price level closer to the flex-price equilibrium which also means that real effects are smaller. These effects arise along the equilibrium path during the adjustment to the new steady state and they are similar to the effects discussed above for the adjustment towards equilibrium in an economy with flexible prices. If we combine the idea that agents need to find the new equilibrium path, convergence towards equilibrium and convergence of equilibrium towards a steady state reinforce each other. An alternative interpretation is that prices are indeed flexible and price stickiness is a mere modelling device for formulating the adjustment process towards the equilibrium that may compete with other models of adjustment processes (sticky information, level $k$, heuristic switching models) for empirical validity. Either way, by relating monetary policy rules to the degree of strategic complementarity, we have pointed to a monetary policy channel that deserves more attention.

\section{References}

Adam, K., 2007. Optimal Monetary Policy with Imperfect Common Knowledge. Journal of Monetary Economics 54, 276-301.

Angeletos, G. M., La'O, J., 2019. Optimal Monetary Policy with Informational Frictions. Journal of Political Economy, forthcoming.

Angeletos, G. M., lovino, L., La'O, J., 2016. Real Rigidity, Nominal Rigidity, and the Social Value of Information. American Economic Review 106, 200-227.

Angeletos, G.-M., Pavan, A., 2007. Efficient Use of Information and Social Value of Information. Econometrica 75, 1103-1142.

Arifovic, J., Duffy, J., 2018. Heterogeneous agent modeling: experimental evidence. In: Hommes, C., LeBaron, B. (Eds.). Handbook of Computational Economics, Vol. 4, Elsevier, 491540.

Assenza, T., Heemeijer, O., Hommes, C., Massaro, D., 2013. Individual expectations and aggregate macro behavior. CeNDEF Working Paper, University of Amsterdam.

Assenza, T., Bao, T., Hommes, C., Massaro, D., 2014. Experiments on Expectations in Macroeconomics and Finance. In: Duffy, J. (Eds.). Experiments in Macroeconomics, Research in Experimental Economics, Vol. 17, Emerald Group Publishing.

Bao, T., Hommes, C., Sonnemans, J., Tuinstra, J., 2012. Individual Expectations, Limited Rationality and Aggregate Outcomes. Journal of Economic Dynamics and Control 36, 11011120.

Bao, T., Zong, J., 2019. The impact of interest rate policy on individual expectations and asset bubbles in experimental markets. Journal of Economic Dynamics and Control 107. https://doi.org/10.1016/i.jedc.2019.103735 
Basu, S., 1995. Intermediate Goods and Business Cycles: Implications for Productivity and Welfare. American Economic Review 85, 512-531.

Benhabib, J., Schmitt-Grohe, S., Uribe, M., 2002. Avoiding Liquidity Traps. Journal of Political Economy 110, 535-563.

Bratsiotis, G., 2007. Monetary Policy Responses and Strategic Price Setting. Economics Letters 95, 327-333.

Cooper, R., John, A., 1988. Coordinating Coordination Failures in Keynesian Models. Quarterly Journal of Economics 103, 441-463.

Duffy, J., 2016. Macroeconomics: A Survey of Laboratory Research. In: Kagel, J. H., Roth, A. E. (Eds.). Handbook of Experimental Economics, Vol. 2, Princeton: Princeton University Press, 190.

Faia, E., 2008. Optimal monetary policy rules with labor market frictions. Journal of Economic Dynamics and Control 32, 1600-1621.

Farhi, E., Werning, I., 2017. Monetary policy, bounded rationality, and incomplete markets. NBER Working paper 23281.

Fehr, E., Tyran, J.-R., 2005. Individual Irrationality and Aggregate Outcomes. Journal of Economic Perspectives 19, 43-66.

Fehr, E., Tyran, J.-R., 2008. Limited Rationality and Strategic Interaction: The Impact of the Strategic Environment on Nominal Inertia. Econometrica 76, 353-394.

Gabaix, X., 2018. A behavioral new Keynesian model. mimeo.

Gali, J., 2008. Monetary Policy, Inflation and the Business Cycle: An Introduction to the New Keynesian Framework. Princeton: Princeton University Press.

Haltiwanger, J., Waldman, M., 1989. Limited Rationality and Strategic Complements: the Implications for Macroeconomics. Quarterly Journal of Economics 104, 463-483.

Heemeijer, P., Hommes, C., Sonnemans, J., Tuinstra, J., 2009. Price Stability and Volatility in Markets with Positive and Negative Expectations Feedback: An Experimental Investigation. Journal of Economic Dynamics and Control 33, 1052-1072.

Hennequin, M., Hommes, C., 2019. Managing bubbles in experimental asset markets with monetary policy. mimeo, http://myrnahennequin.com/.

Hommes, C., 2011. The Heterogeneous Expectations Hypothesis: Some Evidence from the Lab. Journal of Economic Dynamics and Control 35, 1-24.

Hommes, C., 2018. Behavioral \& experimental macroeconomics and policy analysis: a complex systems approach. SSRN Working Paper.

Hommes, C., Massaro, D., Salle, I., 2019. Monetary and fiscal policy design at the zero lower bound: Evidence from the lab. Economic Inquiry 57, 1120-1140. 
Kimball, M.S., 1995. The Quantitative Analytics of the Basic Neomonetarist Model. Journal of Money, Credit and Banking 27, 1241-1277.

Lorenzoni, G., 2009. A Theory of Demand Shocks. American Economic Review 99, 2050-2084.

Lorenzoni, G., 2010. Optimal Monetary Policy with Uncertain Fundamentals and Dispersed Information. Review of Economic Studies 77, 305-338.

Morris, S., Shin, H.S., 2002. Social Value of Public Information. American Economic Review 92, 1522-1534.

Pfajfar, D., Zakelj, B., 2018. Inflation Expectations and Monetary Policy Design: Evidence from the Laboratory. Macroeconomic Dynamics 22, 1035-1075.

Rotemberg, J., Woodford, M., 1995. Dynamic General Equilibrium Models with Imperfectly Competitive Product Markets. In: Cooley, T. F. (Eds.). Frontiers of Business Cycle Research. Princeton: Princeton University Press.

Taylor, J. B., 1993. Discretion Versus Policy Rules in Practice. Carnegie-Rochester Conference Series on Public Policy 39, 195-214.

Woodford, M., 2003. Interest and Prices: Foundations of a Theory of Monetary Policy. Princeton: Princeton University Press. 


\section{Appendix A:}

For our arguments, we do not need to log-linearize the model and can, thus, derive precise results instead of approximations. In this appendix, we first show that determinacy requires $\delta>1+\bar{r}$ if we use the linear feedback rule (21). Then, we show that for the appropriate nonlinear feedback rule that yields the linear rule version as logarithmic approximation, we also get that prices are strategic substitutes if the steady-state equilibrium is determinate.

Combining the non-linearized version of the Fisher equation (31) with feedback rule (21) yields

$$
1+E_{t}\left(\pi_{t+1}\right)=\frac{1+\bar{i}+\delta\left(\pi_{t}-\pi^{*}\right)}{1+r_{t}} .
$$

In a rational expectations equilibrium with flexible prices, the expected real interest rate in future periods is $\bar{r}$. Thus, forwarding the previous equation yields

$$
\begin{gathered}
1+E_{t}\left(\pi_{t+2}\right)=\frac{1+\bar{i}+\delta\left(E_{t}\left(\pi_{t+1}\right)-\pi^{*}\right)}{1+\bar{r}} \\
\Leftrightarrow E_{t}\left(\pi_{t+2}\right)=f\left(E_{t}\left(\pi_{t+1}\right)\right)=\frac{\bar{i}-\bar{r}+\delta\left(E_{t}\left(\pi_{t+1}\right)-\pi^{*}\right)}{1+\bar{r}} .
\end{gathered}
$$

If $f^{\prime}<1 \Leftrightarrow \delta<1+\bar{r}$, any price path with $\pi_{t+1}=f\left(\pi_{t}\right)$ is a rational expectations equilibrium. Here, a change in current inflation also affects expected future inflation, while for $\delta>1+\bar{r}$ the rational expectations equilibrium is determinate and associated with an expected inflation rate of $\pi^{*}$.

The linear Taylor rule was thought for model in logs. Since we have a non-logarithmic model, we might also use a non-logarithmic version of the Taylor rule. Suppose,

$$
1+i_{t}=(1+\bar{i})\left(\frac{1+\pi_{t}}{1+\pi^{*}}\right)^{\delta} .
$$

Then, $\ln \left(1+i_{t}\right)=\ln (1+\bar{i})+\delta\left[\ln \left(1+\pi_{t}\right)-\ln \left(1+\pi^{*}\right)\right] \approx i_{t}=\bar{i}+\delta\left(\pi_{t}-\pi^{*}\right)$. Thus, the linear Taylor rule (21) is a logarithmic approximation of (35).

Combining the Fisher equation (31) with feedback rule (35) yields

$$
1+E_{t}\left(\pi_{t+1}\right)=\frac{1+\bar{i}}{1+r_{t}}\left(\frac{1+\pi_{t}}{1+\pi^{*}}\right)^{\delta} .
$$

In equilibrium the real interest rate must equal the rate of time preference as can be seen from (11): since our economy is not growing, in equilibrium $C_{t+1}=C_{t}$ and $\beta(1+\bar{r})=1$.

Thus, in a rational expectations equilibrium, using $1+\bar{i}=(1+\bar{r})\left(1+\pi^{*}\right)$, implies

$$
\frac{1+E_{t}\left(\pi_{t+1}\right)}{1+\pi^{*}}=f\left(\pi_{t}\right)=\left(\frac{1+\pi_{t}}{1+\pi^{*}}\right)^{\delta} .
$$


Forwarding the equation yields $\frac{1+E_{t}\left(\pi_{t+2}\right)}{1+\pi^{*}}=f\left(\pi_{t}\right)=E_{t}\left(\frac{1+\pi_{t+1}}{1+\pi^{*}}\right)^{\delta}$

If $\delta>1$, then inflation is exploding for any $\pi_{t}>\pi^{*}$ and converges to $-100 \%$ for $\pi_{t}<\pi^{*}$. Applying the usual transversality conditions rules these paths out as equilibria. If $\delta<1$, any price path with $\pi_{t+1}=f\left(\pi_{t}\right)$ is a rational expectations equilibrium. Here, a change in current inflation also affects expected future inflation, while for $\delta>1$ the rational expectations equilibrium is determinate and associated with an expected inflation rate of $E_{t} \pi_{t+1}=\pi^{*}$.

Replacing the interest rate in (19) with (35) gives

$$
P_{t}(j)=\frac{\varepsilon}{\varepsilon-1} P_{t}\left[\left((1+\bar{i})\left(\frac{P_{t}}{P_{t-1}\left(1+\pi^{*}\right)}\right)^{\delta}\right) \beta \frac{E_{t}\left(C_{t+1}^{-\sigma}\right)}{1+\pi^{*}}\right]^{\frac{-(\phi+\sigma)}{\sigma}} .
$$

Taking the derivative with respect to $P_{t}$ and rearranging terms gives

$$
\frac{\partial P_{t}(j)}{\partial P_{t}}=\frac{P_{t}(j)}{P_{t}}\left(1-\frac{\phi+\sigma}{\sigma} \delta\right) .
$$

Hence, we find that prices are strategic substitutes for $\delta>1$. 
Appendix B: Log-linearized approximation

Here, we use the log-linearized approximations of equilibrium conditions to explain the relation between determinacy and strategic substitutability. The log-linearized version of the best response function in equation (19) is

$$
\ln P_{t}(j)=\ln \frac{\varepsilon}{\varepsilon-1}+\ln P_{t}-\frac{(\phi+\sigma)}{\sigma}\left[\ln \left(1+i_{t}\right)+\ln \beta+\ln E_{t}\left(\frac{C_{t+1}^{-\sigma}}{1+\pi_{t+1}}\right)\right] .
$$

Inserting the feedback rule for the interest rate (21) into the approximation of (36) gives

$$
\begin{aligned}
& \ln P_{t}(j) \approx \ln \frac{\varepsilon}{\varepsilon-1}+\ln P_{t}-\frac{(\phi+\sigma)}{\sigma}\left[i_{t}+\ln \beta+\ln E_{t}\left(\frac{C_{t+1}^{-\sigma}}{1+\pi_{t+1}}\right)\right] \\
& \quad=\ln \frac{\varepsilon}{\varepsilon-1}+\ln P_{t}-\frac{(\phi+\sigma)}{\sigma}\left[\bar{i}+\delta\left(\pi_{t}-\pi^{*}\right)+\ln \beta+\ln E_{t}\left(\frac{C_{t+1}^{-\sigma}}{1+\pi_{t+1}}\right)\right] .
\end{aligned}
$$

If $\delta>1$, then inflation is exploding for any $\pi_{t}>\pi^{*}$ and converges to $-100 \%$ for $\pi_{t}<\pi^{*}$. Applying the usual transversality conditions rules these paths out as equilibria and leaves us with an expected future inflation $\pi_{t+1}=\pi^{*}$ as the only rational expectations equilibrium. Thus,

$$
\ln P_{t}(j) \approx \ln \frac{\varepsilon}{\varepsilon-1}+\ln P_{t}-\frac{(\phi+\sigma)}{\sigma}\left[\bar{i}+\delta\left(\ln P_{t}-\ln P_{t-1}-\pi^{*}\right)+\ln \beta+\ln E_{t}\left(\frac{C_{t+1}^{-\sigma}}{1+\pi^{*}}\right)\right],
$$

and

$$
\frac{\partial \ln P_{t}(j)}{\partial \ln P_{t}} \approx 1-\frac{(\phi+\sigma)}{\sigma} \delta .
$$

For $\delta>1$, this derivative is negative and, thus, prices are strategic substitutes.

At the zero lower bound, the interest rate $i_{t}=0$ and the best response function (36) is

$$
\begin{gathered}
\ln P_{t}(j)=\ln \frac{\varepsilon}{\varepsilon-1}+\ln P_{t}-\frac{(\phi+\sigma)}{\sigma}\left[\ln \beta+\ln E_{t}\left(\frac{C_{t+1}^{-\sigma}}{1+\pi_{t+1}}\right)\right] \\
=\ln \frac{\varepsilon}{\varepsilon-1}+\ln P_{t}-\frac{(\phi+\sigma)}{\sigma}\left[\ln \beta+\ln E_{t}\left(\frac{C_{t+1}^{-\sigma}}{1+\pi^{L}}\right)\right],
\end{gathered}
$$

where $\pi^{L}<\pi^{*}$ is the inflation rate in the liquidity trap equilibrium. The demand effect is muted because the interest rate does not respond to prices and

$$
\frac{\partial \ln P_{t}(j)}{\partial \ln P_{t}}=1
$$

If $\delta<1$, the equilibrium is indeterminate and the expected future rate of inflation depends positively on the current rate of inflation. Therefore, a higher current price level, increases 
expected future inflation, which opens an additional channel. Combining the Fisher equation, $i_{t}-\bar{r} \approx E_{t}\left(\pi_{t+1}\right)$, with feedback rule (21) yields

$$
E_{t}\left(\pi_{t+1}\right)=f\left(\pi_{t}\right) \approx \bar{i}-\bar{r}+\delta\left(\pi_{t}-\pi^{*}\right) .
$$

Feeding this expectation into the best response function (37) gives

$$
\begin{aligned}
& \ln P_{t}(j) \approx \ln \frac{\varepsilon}{\varepsilon-1}+\ln P_{t}-\frac{(\phi+\sigma)}{\sigma}\left[\bar{i}+\delta\left(\pi_{t}-\pi^{*}\right)+\ln \beta+\ln E_{t}\left(C_{t+1}^{-\sigma}\right)-E_{t}\left(\pi_{t+1}\right)\right] \\
& \quad \approx \ln \frac{\varepsilon}{\varepsilon-1}+\ln P_{t}-\frac{(\phi+\sigma)}{\sigma}\left[\bar{i}+\delta\left(\pi_{t}-\pi^{*}\right)+\ln \beta+\ln E_{t}\left(C_{t+1}^{-\sigma}\right)-\bar{i}+\bar{r}-\delta\left(\pi_{t}-\pi^{*}\right)\right] \\
& \quad=\ln \frac{\varepsilon}{\varepsilon-1}+\ln P_{t}-\frac{(\phi+\sigma)}{\sigma}\left[\ln \beta+\ln E_{t}\left(C_{t+1}^{-\sigma}\right)+\bar{r}\right] .
\end{aligned}
$$

As in the liquidity trap, the demand effect is also muted, but for a different reason. Here, the interest rate rises in response to increasing prices, but expected future prices rise along and the real rate is not affected by current price changes. Thus, there is no shift in demand and

$$
\frac{\partial \ln P_{t}(j)}{\partial \ln P_{t}} \approx 1
$$

Thus, in all indeterminate equilibria, prices are strategic complements. 